\title{
Effects of Vortioxetine on depression model rats and expression of BDNF and Trk B in hippocampus
}

\author{
BAOMIN SUN ${ }^{1}$, YANHUA LV ${ }^{2}$, HUA XU $^{3}, \mathrm{CHUNHUA} \mathrm{QI}^{4}, \mathrm{CUIPING} \mathrm{LI}^{1}$ and PENGFEI LIU ${ }^{1}$ \\ ${ }^{1}$ Department of Psychology, Taian City Central Hospital; ${ }^{2}$ Department of Psychiatry, Taian City Mental Hospital; \\ ${ }^{3}$ Department of Neurology and ${ }^{4}$ Central Laboratory, Taian City Central Hospital, Taian, Shandong 271000, P.R. China
}

Received September 18, 2019; Accepted April 15, 2020

DOI: $10.3892 / \mathrm{etm} .2020 .9026$

\begin{abstract}
Effects of Vortioxetine on the expression of brain-derived neurotrophic factor (BDNF) and tyrosine kinase B (Trk B) in hippocampus of depressive rats were investigated. Forty-five SD rats were randomly divided into three groups: model control, Vortioxetine and normal control group, with 15 rats in each group. The changes of body mass were recorded within 5 weeks, and the open field test, sugar water preference test and Morris water maze test were performed to evaluate the behavior and mental status of the rats. The expression of BDNF and Trk B in rat hippocampus was detected by enzyme-linked immuno sorbent assay. Compared with the model control group, the body mass, horizontal and vertical movement, sugar and water preference rate of the vortioxetine group in the 5 th week were significantly higher than those of the model control group $(\mathrm{P}<0.05)$, and significantly lower than those of the normal control group $(\mathrm{P}<0.05)$. The escape latency of the Vortioxetine group within 4 days was significantly lower than that of model control group $(\mathrm{P}<0.05)$, but higher than that of normal control group $(\mathrm{P}<0.05)$. The target quadrant residence time of the Vortioxetine group was significantly lower than that of the model control group $(\mathrm{P}<0.05)$, but higher than that of the normal control group $(\mathrm{P}<0.05)$. Expression of BDNF and Trk $\mathrm{B}$ in the Vortioxetine group was significantly higher than that in the model control group $(\mathrm{P}<0.05)$, but lower than that of the normal control group $(\mathrm{P}<0.05)$. Collectively, Vortioxetine can effectively alleviate the symptoms of autonomous and exploratory behavior, and reduce the decrease of learning and memory in depressive rats. Vortioxetine can increase the expression of BDNF and Trk B in depressive rats and alleviate their depressive behavior.
\end{abstract}

Correspondence to: Dr Yanhua Lv, Department of Psychiatry, Taian City Mental Hospital, 2 Changcheng Road, Taian, Shandong 271000, P.R. China

E-mail: uaekg4@163.com

Key words: vortioxetine, depression, brain-derived neurotrophic factor, tyrosine kinase B

\section{Introduction}

Depression is a common mental illness that can lead to upset or anxiety. The disease has a high incidence rate in the world. Some depressive patients often have suicidal thoughts and behavior, or experience mental illness symptoms such as fantasy or delusion (1). World Health Organization statistics show that more than 300 million people worldwide suffer from depression, which is equivalent to $4.4 \%$ of the total population in the world. Depression is also the main cause of disability and suicide worldwide, $7.5 \%$ patients suffer from disability, and nearly 800,000 people die of suicide due to depression every year (2). It has been reported that the annual cost of depression treatment in the United States is close to $\$ 23$ billion, which places huge economic burden and loss to patients and society (3).

Many studies have shown that depression is associated with neurotrophic factors in patients, the most prominent of which is brain-derived neurotrophic factor (BDNF). Stress and depression reduce the expression and function of BDNF, while typical antidepressant therapies increase BDNF expression and block the growth factor expression deficits caused by stress and depression (4). Su et al (5) found that the levels of BDNF protein and mRNA in hippocampus of depressive mice were significantly reduced by learned helplessness. Zhou et al (6) reported that peripheral BDNF levels will increase during the treatment of antidepressants. BDNF can play an antidepressant role by mediating downstream signal transduction through its receptor tyrosine kinase B (Trk B). Overexpression of Trk B in mice stimulates astrocyte production and increases the number of young neurons, reduces despair and basal corticosterone levels (7). It has been reported that BDNF and Trk B are mainly distributed in the hippocampus for synaptic transmission (8).

Vortioxetine is a novel multi-target antidepressant for severe depression. With multi-modal antidepressant mechanism, it not only induces antidepressant or anti-anxiety activities, but also improves the cognitive parameters of young adult rodents and old animal models $(9,10)$. Compared with some common antidepressants, Vortioxetine has higher remission rate, lower incidence of adverse events and better tolerance (11-13). It has been reported that Vortioxetine may have a therapeutic effect on cognitive aspects such as executive function, attention, learning and memory that may exceed standard antidepressants $(14,15)$. However, it is still unclear how Vortioxetine 
works on the depression model rats and the expression of BDNF and Trk B in hippocampus.

Therefore, this study explored the expression of BDNF and Trk B in hippocampus by observing the behavior and mental status of Vortioxetine in the treatment of depressive rats, so as to provide reference for clinical practice.

\section{Materials and methods}

General materials. Forty-five healthy adult SD male rats, aged 10-12 weeks and weight of 200-250 gr were used in this study. They were purchased from Shanghai Branch of Beijing Vitonglihua Laboratory Animal Technology Co., Ltd., with license number SCXK (Shanghai) 2017-0011. They were randomly divided into model control, Vortioxetine and normal control group, with 15 rats in each group. Rats had free access to food and water, $12 \mathrm{~h}$ light/12 $\mathrm{h}$ dark, and the temperature kept at $21 \pm 2^{\circ} \mathrm{C}$ for 7 days, so that the rats could adapt to the laboratory environment. On the 8th day, depression models were constructed in the model control and Vortioxetine group. The normal control group did not receive any treatment for 21 days. On the 29th day, rats in the Vortioxetine group were given intraperitoneal injection of Vortioxetine $(24 \mathrm{mg}$ / $\mathrm{kg}$ /day) (15), while rats in the model control and the normal control group were given normal saline $(8 \mathrm{ml} / \mathrm{kg} / \mathrm{day})$ for 7 days. The body mass data of rats were collected once a week from the first week for 5 weeks. The study was approved by the Animal Ethics Committee of Taian City Central Hospital (Taian, China) (no. TCH19001B).

Kits and reagents. Vortioxetine (Shantou Jinshi Pharmaceutical Co., Ltd. of China Pharmaceutical Group, SFDA Approval No. H44021505), BDNF enzyme-linked immuno sorbent assay (ELISA) kit (Wuhan Elabscience Biotechnology Co., Ltd.; E-EL-R1235c), Trk B ELISA kit (MyBioSource, Inc., MBS161365).

Establishing depression model rats. Rats randomly received 7 sources of stimulation: i) Rats had no access to food and water for $24 \mathrm{~h}$, ii) rats were placed in a light and dark cycle reversed environment, iii) rats were suddenly placed in $4^{\circ} \mathrm{C}$ ice water to force them to swim for $5 \mathrm{~min}$, and immediately dried in a $30^{\circ} \mathrm{C}$ greenhouse. Rectal temperature was measured before and after the intervention. The rectal temperature was $36.98 \pm 0.30^{\circ} \mathrm{C}$ before the intervention and the body temperature was $37.10 \pm 0.22^{\circ} \mathrm{C}$ after the intervention, iv) rats were suddenly forced to swim in warm water at $45^{\circ} \mathrm{C}$ for 5 min, and immediately dried in a greenhouse at $30^{\circ} \mathrm{C}$. Rectal temperature was measured before and after the intervention. The rectal temperature was $36.98 \pm 0.30^{\circ} \mathrm{C}$ before the intervention and the body temperature was $37.10 \pm 0.22^{\circ} \mathrm{C}$ after the intervention, v) $50 \mathrm{~V}$ voltage click on sole, $50 \mathrm{sec}$ interval, $10 \mathrm{sec}$ each time, a total of 30 times, vi) tail clamp for $1 \mathrm{~min}$ and vii) cage tilt $45^{\circ}$ for $24 \mathrm{~h}$. All rats received different stimuli every day, and the same stimuli did not appear within 3 days $(16,17)$. The modeling time lasted for 21 days, and the difference between behavioral experiment and normal control group was significant, which indicated that the model was successfully established. The third intervention was performed twice, and rectal temperature was measured before and after the intervention. The temperature changes before and after the two interventions were $0.92 \pm 0.26^{\circ} \mathrm{C}$ and $0.84 \pm 0.30^{\circ} \mathrm{C}$. The fourth intervention was performed 3 times. Rectal temperature were measured before and after the intervention. The temperature changes before and after the intervention were $1.04 \pm 0.31^{\circ} \mathrm{C}, 1.10 \pm 0.28^{\circ} \mathrm{C}$, and $1.14 \pm 0.33^{\circ} \mathrm{C}$. None of the rats had excessively high or low body temperature.

Open field test. A 100x100x50 cm test box was used, with black perimeter wall, and the bottom of the box was divided into 25 squares of equal area by white lines. The rats were placed in the center of the test box and measured for $4 \mathrm{~min}$ each time. The number of blocks crossing the ground was horizontal motion score and the number of upright was vertical motion score. After each rat was tested, alcohol was used to wipe the test box, and the test process was recorded by video camera. The test was done once a week at a fixed time for 5 weeks.

Sugar-water preference experiment. After fasting for $23 \mathrm{~h}$, two bottles containing $1 \%$ sucrose liquid and water were put into each cage. The positions of the two bottles were replaced 30 min later. The volume of water and sucrose consumed by each rat within $1 \mathrm{~h}$ was measured. Sucrose preference ratio $=$ the volume of consumed sucrose solution / (the volume of consumed sucrose solution + the volume of consumed water) $\mathrm{x} 100 \%$, determined once a week for 5 weeks.

Morris water maze test. The test was conducted on the 36th day. The positioning navigation test was performed in the first 4 days. Rats were placed in water, and the time elapsed from the starting point to the platform for each rat was recorded as the escape latency time. If the rat did not find the platform within $60 \mathrm{sec}$, it was directed to it and allowed to stay on the platform for $15 \mathrm{sec}$, and the escape latency was recorded as $60 \mathrm{sec}$. On the fifth day, the platform was removed for space exploration experiment. Rats were put into the water from the farthest quadrant of the platform. The swimming time of rats in the original quadrant of the platform was recorded as the memory time within $60 \mathrm{sec}$.

Test sample collection. One day after the Morris water maze test, rats were anesthetized with $5 \%$ pentobarbital $(50 \mathrm{mg} / \mathrm{kg}$; intraperitoneal injection), then the whole brain was removed by decapitation, and the hippocampus tissue was carefully separated on ice, and stored at $-80^{\circ} \mathrm{C}$.

Detection of BDNF and Trk $B$ expression in hippocampus by ELISA. The hippocampus tissue was weighed and reset in a homogenizer, and the lysis buffer (50 mM Tris, $150 \mathrm{mM} \mathrm{NaCl}, 1 \% \mathrm{NP}-40,0.5 \%$ sodium deoxycholate) was added to centrifuge at $1,500 \mathrm{x}$ for $20 \mathrm{~min}$ at $4^{\circ} \mathrm{C}$, and the supernatant was collected. The expression of BDNF and Trk B in supernatant was detected by ELISA. Blank wells, standard wells and sample wells were tested. Standard SO with a concentration of 0 was added into blank well and $50 \mu 1$ of different concentration standard was added to the standard well. Sample wells were first added with $10 \mu \mathrm{l}$ of the sample to be tested, followed by $40 \mu \mathrm{l}$ of the sample dilution solution. In addition to the blank wells, $100 \mu$ l of horseradish peroxidase 
Table I. Body mass in three groups within 5 weeks (gr).

\begin{tabular}{lccccccc}
\hline Group & 1st week & 2nd week & 3rd week & 4th week & 5th week & F-value & P-value \\
\hline $\begin{array}{l}\text { Normal control } \\
\text { group (n=15) }\end{array}$ & $228.63 \pm 7.85$ & $256.07 \pm 11.32^{\mathrm{c}}$ & $278.69 \pm 13.48^{\mathrm{c}, \mathrm{d}}$ & $297.74 \pm 16.58^{\mathrm{c}-\mathrm{e}}$ & $321.55 \pm 18.34^{\mathrm{c}-\mathrm{f}}$ & 99.083 & $<0.001$ \\
$\begin{array}{l}\text { Model control } \\
\text { group (n=15) }\end{array}$ & $231.65 \pm 8.52$ & $241.37 \pm 9.33^{\mathrm{a}, \mathrm{c}}$ & $252.26 \pm 10.70 \mathrm{~A}^{\mathrm{a}, \mathrm{c}, \mathrm{d}}$ & $264.41 \pm 12.04^{\mathrm{a}, \mathrm{c} \text { - }}$ & $271.74 \pm 13.32^{\mathrm{a}, \mathrm{c}-\mathrm{f}}$ & 30.557 & $<0.001$ \\
$\begin{array}{l}\text { Vortioxetine } \\
\text { group (n=15) }\end{array}$ & $227.32 \pm 7.38$ & $238.69 \pm 9.13 \mathrm{~A}^{\mathrm{a}, \mathrm{c}}$ & $253.15 \pm 11.25 \mathrm{~A}^{\mathrm{a}, \mathrm{c}, \mathrm{d}}$ & $266.28 \pm 12.57^{\mathrm{a}, \mathrm{c} \text { - }}$ & $293.63 \pm 16.32^{\mathrm{a}-\mathrm{f}}$ & 57.629 & $<0.001$ \\
F-value & 1.176 & 13.197 & 23.979 & 27.309 & 35.953 & & \\
P-value & 0.319 & $<0.001$ & $<0.001$ & $<0.001$ & $<0.001$ & & \\
\hline
\end{tabular}

${ }^{\mathrm{a}} \mathrm{P}<0.05$, compared with the normal control group; ${ }^{\mathrm{b}} \mathrm{P}<0.05$, compared with the model control group; ${ }^{\mathrm{c}} \mathrm{P}<0.05$, compared with the $1 \mathrm{st}$ week in the same group; ${ }^{\mathrm{d}} \mathrm{P}<0.05$, compared with the 2 nd week in the same group; ${ }^{\mathrm{P}} \mathrm{P}<0.05$, compared with the $3 \mathrm{rd}$ week in the same group; $\mathrm{P}<0.05$, compared with the 4 th week in the same group.

(HRP)-labeled detection antibody was added to each well of the standard wells and the sample wells. The reaction well was sealed with a sealing film, incubated at $37^{\circ} \mathrm{C}$ in a water bath for $65 \mathrm{~min}$, the liquid was discarded, and dried with absorbent paper. Each well was filled with washing solution and allowed to stand for $2 \mathrm{~min}$, then washing solution was discarded, patting dry with absorbent paper, repeated 6 times. Substrate A $(50 \mu \mathrm{l})$ and B $(50 \mu \mathrm{l})$ were added to each well, incubated at $37^{\circ} \mathrm{C}$ for $10 \mathrm{~min}$ avoiding light. A total of $50 \mu \mathrm{l}$ of the termination solution was added to each well, and the OD value of each well was measured at a wavelength of $450 \mathrm{~nm}$ within $15 \mathrm{~min}$. The concentration was calculated.

Observation indicators. The following indicators were observed: Changes of body mass during the first five weeks; scores of horizontal and vertical motion; sucrose preference rate; escape latency in the first four days of Morris water maze and target quadrant residence time on the last day; and expression levels of BDNF and Trk B in the hippocampus.

Statistical analysis. SPSS 20.0 (IBM Corp.) medical statistical analysis software was used to analyze the collected data. GraphPad Prism 7 (San Diego Grapad Software Co., Ltd.) was used to illustrate the collected data. Chi-square test was used for counting data $(\%)$, expressed as $\chi^{2}$. The normal distributed data were expressed as mean \pm standard deviation (mean $\pm \mathrm{SD}$ ). One-way ANOVA followed by LSD-t test was used for comparison among three or more groups. Repeated ANOVA test was used for comparison at multiple time points within the group, and the post hoc test was the Bonferroni test. F was used for comparison, and $\mathrm{P}<0.05$ was considered statistically significant.

\section{Results}

Changes of body mass in three groups within 5 weeks. There was no significant difference in body mass among the three groups in the first week $(\mathrm{P}>0.05)$. There was no significant difference between the Vortioxetine group and the model control group in the 2 nd, 3rd and 4 th weeks $(\mathrm{P}>0.05)$, and the body mass was significantly lower than that of the normal control group $(\mathrm{P}<0.05)$. At the 5 th week, the body mass of Vortioxetine group was significantly higher than that of the control group $(\mathrm{P}<0.05)$, and significantly lower than that of normal control group $(\mathrm{P}<0.05)$, and the body mass of the three groups increased markedly within five weeks $(\mathrm{P}<0.05)$, as shown in Table I.

Field test movement in three groups in 5 weeks. Horizontal and vertical movement in 5 weeks in the three groups was compared. There was no significant difference between horizontal and vertical movement in the normal control group ( $\mathrm{P}>0.05)$. There was no significant difference between horizontal and vertical movement in three groups in the first week $(\mathrm{P}>0.05)$. Horizontal and vertical motion of Vortioxetine group and model control group in the 2nd, 3rd and 4th weeks were significantly lower than those in the first week $(\mathrm{P}<0.05)$. There was no significant difference between Vortioxetine group and model control group $(\mathrm{P}>0.05)$, and the difference was significantly lower than that of normal control group $(\mathrm{P}<0.05)$. In the fifth week, the horizontal and vertical moves in the Vortioxetine group were significantly lower than those in the first and second weeks $(\mathrm{P}<0.05)$, significantly higher than those in the 4 th week $(\mathrm{P}<0.05)$, and there was no significant difference compared with those in the 3 rd week $(P>0.05)$. In the fifth week, the horizontal and vertical moves of the model control group were significantly lower than those of the first, second and third weeks $(\mathrm{P}<0.05)$. There was no significant difference compared with the fourth week $(\mathrm{P}>0.05)$. The horizontal and vertical moves of the Vortioxetine group were significantly higher than those of the model control group $(\mathrm{P}<0.05)$, and significantly lower than those of the normal control group $(\mathrm{P}<0.05)$ (Tables II and III).

Sugar and water preference rate in three groups within 5 weeks. According to the sugar water test, there was no significant change in the sugar water preference rate within 5 weeks in the normal control group $(\mathrm{P}>0.05)$. It was found that there was no significant difference in the preference rate of sugar and water among the three groups in the first week $(\mathrm{P}>0.05)$, and the preference rate of sugar and water in the 2nd, 3rd and 4th weeks of Vortioxetine group and model 
Table II. Horizontal motion of field tests in three groups in 5 weeks.

\begin{tabular}{lccccccr}
\hline Group & 1 st week & 2 nd week & 3rd week & 4th week & 5th week & F-value & P-value \\
\hline $\begin{array}{l}\text { Normal control } \\
\text { group (n=15) }\end{array}$ & $27.83 \pm 8.21$ & $26.79 \pm 7.83$ & $27.21 \pm 7.86$ & $27.14 \pm 7.59$ & $27.57 \pm 7.61$ & 0.780 & 0.529 \\
$\begin{array}{l}\text { Model control } \\
\text { group (n=15) }\end{array}$ & $27.14 \pm 7.73$ & $20.84 \pm 6.19^{\mathrm{a}, \mathrm{c}}$ & $14.88 \pm 5.70^{\mathrm{a}, \mathrm{c}, \mathrm{d}}$ & $8.83 \pm 3.94^{\mathrm{a}, \mathrm{c}-\mathrm{e}}$ & $9.02 \pm 4.15^{\mathrm{a}, \mathrm{c}-\mathrm{e}}$ & 31.926 & $<0.001$ \\
$\begin{array}{l}\text { Vortioxetine } \\
\text { group (n=15) }\end{array}$ & $26.33 \pm 7.52$ & $21.27 \pm 6.22^{\mathrm{a}, \mathrm{c}}$ & $15.75 \pm 5.25^{\mathrm{a}, \mathrm{c}, \mathrm{d}}$ & $8.58 \pm 3.71^{\mathrm{a}, \mathrm{c}-\mathrm{e}}$ & $13.68 \pm 5.24^{\mathrm{a}-\mathrm{c}, \mathrm{d}, \mathrm{f}}$ & 21.438 & $<0.001$ \\
$\begin{array}{l}\text { F-value } \\
\text { P-value }\end{array}$ & 0.152 & 3.582 & 17.490 & 58.673 & 40.847 & & \\
\hline
\end{tabular}

${ }^{\mathrm{a}} \mathrm{P}<0.05$, compared with the normal control group; ${ }^{\mathrm{b}} \mathrm{P}<0.05$, compared with the model control group; ${ }^{\mathrm{c}} \mathrm{P}<0.05$, compared with the 1 st week in the same group; ${ }^{\mathrm{d}} \mathrm{P}<0.05$, compared with the 2 nd week in the same group; ${ }^{\mathrm{e}} \mathrm{P}<0.05$, compared with the 3 rd week in the same group; ${ }^{\mathrm{f}} \mathrm{P}<0.05$, compared with the 4 th week in the same group.

Table III. Vertical movement of three groups of field tests in 5 weeks.

\begin{tabular}{|c|c|c|c|c|c|c|c|}
\hline Group & 1st week & 2nd week & 3rd week & 4 th week & 5th week & F-value & P-value \\
\hline $\begin{array}{l}\text { Normal control } \\
\text { group }(n=15)\end{array}$ & $5.13 \pm 1.25$ & $4.63 \pm 1.17$ & $4.86 \pm 1.20$ & $4.87 \pm 1.20$ & $4.75 \pm 1.18$ & 0.873 & 0.467 \\
\hline $\begin{array}{l}\text { Model control } \\
\text { group }(n=15)\end{array}$ & $4.88 \pm 1.19$ & $3.14 \pm 0.82^{\mathrm{a}, \mathrm{c}}$ & $2.53 \pm 0.77^{\mathrm{a}, \mathrm{c}, \mathrm{d}}$ & $1.79 \pm 0.62^{\mathrm{a}, \mathrm{c}-\mathrm{e}}$ & $1.83 \pm 0.63^{\mathrm{a}, \mathrm{c}-\mathrm{e}}$ & 41.686 & $<0.001$ \\
\hline $\begin{array}{l}\text { Vortioxetine } \\
\text { group }(n=15)\end{array}$ & $4.74 \pm 1.15$ & $3.26 \pm 0.86^{\mathrm{a}, \mathrm{c}}$ & $2.64 \pm 0.74^{\mathrm{a}, \mathrm{c}, \mathrm{d}}$ & $1.84 \pm 0.67^{\mathrm{a}, \mathrm{c}-\mathrm{e}}$ & $3.46 \pm 0.87^{a-c, e, f}$ & 13.600 & $<0.001$ \\
\hline F-value & 0.408 & 11.088 & 30.992 & 61.595 & 37.843 & & \\
\hline P-value & 0.667 & $<0.001$ & $<0.001$ & $<0.001$ & $<0.001$ & & \\
\hline
\end{tabular}

${ }^{\mathrm{a}} \mathrm{P}<0.05$, compared with the normal control group; ${ }^{\mathrm{b}} \mathrm{P}<0.05$, compared with the model control group; ${ }^{\mathrm{c}} \mathrm{P}<0.05$, compared with the 1 st week in the same group; ${ }^{\mathrm{d}} \mathrm{P}<0.05$, compared with the 2 nd week in the same group; ${ }^{\mathrm{e}} \mathrm{P}<0.05$, compared with the 3 rd week in the same group; ${ }^{\mathrm{f}}<0.05$, compared with the 4th week in the same group.

Table IV. Sugar and water preference rate $(\%)$ within 5 weeks in three groups.

\begin{tabular}{|c|c|c|c|c|c|c|c|}
\hline Group & 1st week & 2nd week & 3rd week & 4 th week & 5 th week & F-value & $P$ value \\
\hline $\begin{array}{l}\text { Normal control } \\
\text { group }(n=15)\end{array}$ & $85.13 \pm 8.78$ & $82.24 \pm 7.62$ & $83.87 \pm 8.69$ & $86.37 \pm 7.84$ & $87.16 \pm 7.62$ & 2.290 & 0.090 \\
\hline $\begin{array}{l}\text { Model control } \\
\text { group }(n=15)\end{array}$ & $87.43 \pm 9.23$ & $73.14 \pm 8.85^{\mathrm{a}, \mathrm{c}}$ & $66.37 \pm 7.24^{\mathrm{a}, \mathrm{c}, \mathrm{d}}$ & $58.21 \pm 6.98^{\mathrm{a}, \mathrm{c}-\mathrm{e}}$ & $60.47 \pm 7.36^{\mathrm{a}, \mathrm{c}-\mathrm{e}}$ & 26.846 & $<0.001$ \\
\hline $\begin{array}{l}\text { Vortioxetine } \\
\text { group }(n=15)\end{array}$ & $84.57 \pm 8.36$ & $75.82 \pm 9.48^{\mathrm{a}, \mathrm{c}}$ & $65.42 \pm 7.52^{\mathrm{a}, \mathrm{c}, \mathrm{d}}$ & $53.58 \pm 7.35^{\mathrm{a}, \mathrm{c}-\mathrm{e}}$ & $71.69 \pm 6.24^{\mathrm{a}-\mathrm{c}, \mathrm{e}, \mathrm{f}}$ & 26.527 & $<0.001$ \\
\hline F-value & 0.445 & 4.349 & 26.326 & 86.305 & 53.461 & & \\
\hline P-value & 0.644 & 0.019 & $<0.001$ & $<0.001$ & $<0.001$ & & \\
\hline
\end{tabular}

${ }^{\mathrm{a}} \mathrm{P}<0.05$, compared with the normal control group; ${ }^{\mathrm{b}} \mathrm{P}<0.05$, compared with the model control group; ${ }^{\mathrm{c}} \mathrm{P}<0.05$, compared with the 1 st week in the same group; ${ }^{\mathrm{d}} \mathrm{P}<0.05$, compared with the 2 nd week in the same group; ${ }^{\mathrm{P}} \mathrm{P}<0.05$, compared with the 3 rd week in the same group; $\mathrm{P}<0.05$, compared with the 4 th week in the same group.

control group was significantly lower than that in the previous weeks $(\mathrm{P}<0.05)$. There was no significant difference in sugar preference rate between Vortioxetine and model control group $(P>0.05)$, and it was significantly lower than that of normal control group $(\mathrm{P}<0.05)$. Sugar preference rate of Vortioxetine group in the fifth week was significantly lower than that in the first week $(\mathrm{P}<0.05)$, significantly higher than that in the fourth and fifth weeks $(\mathrm{P}<0.05)$, and there was no difference 
Table V. Escape latency (S) of three groups in positioning and navigation test.

\begin{tabular}{|c|c|c|c|c|c|c|}
\hline Group & 1st day & 2nd day & 3rd day & 4th day & F-value & P-value \\
\hline Normal control group $(n=15)$ & $34.63 \pm 3.78$ & $26.46 \pm 3.62^{c}$ & $21.48 \pm 2.66^{\mathrm{c}, \mathrm{d}}$ & $16.79 \pm 2.54^{\mathrm{c}-\mathrm{e}}$ & 82.141 & $<0.001$ \\
\hline Model control group $(n=15)$ & $55.84 \pm 6.72^{\mathrm{a}}$ & $51.65 \pm 6.49^{\mathrm{a}}$ & $47.26 \pm 6.13^{\mathrm{a}, \mathrm{c}, \mathrm{d}}$ & $42.14 \pm 5.46^{\mathrm{a}, \mathrm{c}-\mathrm{e}}$ & 22.932 & $<0.001$ \\
\hline Vortioxetine group $(n=15)$ & $46.83 \pm 4.85^{\mathrm{a}}$ & $41.92 \pm 4.57^{\mathrm{a}, \mathrm{c}}$ & $37.67 \pm 4.76^{\mathrm{a}, \mathrm{c}, \mathrm{d}}$ & $31.73 \pm 3.45^{\mathrm{a}-\mathrm{e}}$ & 45.955 & $<0.001$ \\
\hline F-value & 61.458 & 95.411 & 113.507 & 151.694 & & \\
\hline P-value & $<0.001$ & $<0.001$ & $<0.001$ & $<0.001$ & & \\
\hline
\end{tabular}

${ }^{\text {a }} \mathrm{P}<0.05$, compared with the normal control group; ${ }^{\text {}} \mathrm{P}<0.05$, compared with the model control group; ${ }^{\mathrm{c}} \mathrm{P}<0.05$, compared with the 1 st day in the same group; ${ }^{\mathrm{d}} \mathrm{P}<0.05$, compared with the 2 nd day in the same group; ${ }^{\mathrm{e}} \mathrm{P}<0.05$, compared with the 3rd day in the same group.

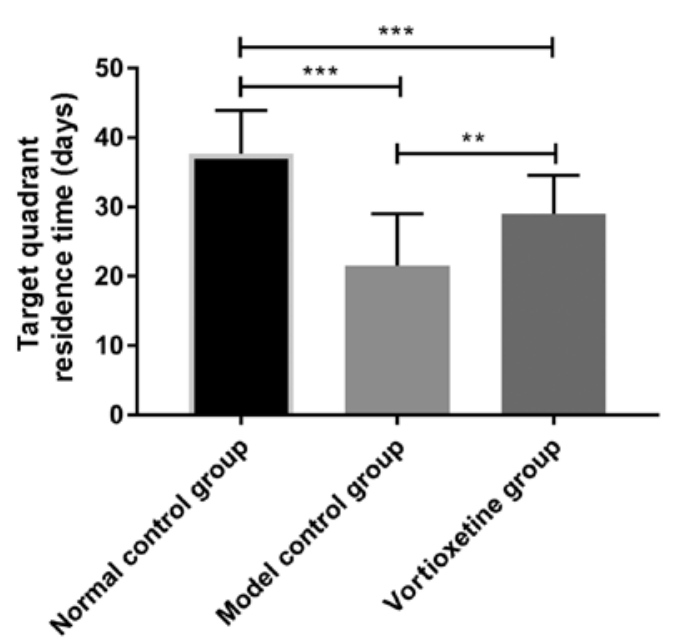

Figure 1. Target quadrant residence time of three groups in space exploration experiments. The purpose quadrant dwell time of Vortioxetine group was significantly higher than that of model control group $(\mathrm{P}=0.003)$, but lower than that of normal control group $(\mathrm{P}<0.001)$, and that of model control group was significantly lower than that of normal control group $(\mathrm{P}<0.001)$. ${ }^{* * *} \mathrm{P}<0.01 ;{ }^{* * *} \mathrm{P}<0.001$.

compared with that in the second week $(\mathrm{P}>0.05)$. Sugar and water preference rate of week 5 in the model control group was significantly lower than that of week 1,2 and $3(\mathrm{P}<0.05)$, and there was no significant difference compared with that of week $4(\mathrm{P}>0.05)$. Sugar and water preference rate of week 5 in the Vortioxetine group was significantly higher than that in the model control group $(\mathrm{P}<0.05)$, and significantly lower than that in the normal control group $(\mathrm{P}<0.05)$ (Table IV).

Morris water maze learning and memory ability. Morris water maze experiment was used to compare the escape latency of three groups in positioning navigation test and the target quadrant residence time in space exploration experiment. It was found that the escape latency of three groups decreased significantly within four days $(\mathrm{P}<0.05)$. The escape latency of Vortioxetine group was significantly lower than that of model control group $(\mathrm{P}<0.05)$, but higher than that of normal control group $(\mathrm{P}<0.05)$. The target quadrant dwell time $(28.96 \pm 5.62 \mathrm{sec})$ of Vortioxetine group was significantly lower than that of model control group $(21.54 \pm 7.49 \mathrm{sec})(\mathrm{P}<0.05)$, but higher than that of normal control group $(37.64 \pm 6.25 \mathrm{sec})$ $(\mathrm{P}<0.05)$ (Table V and Fig. 1).
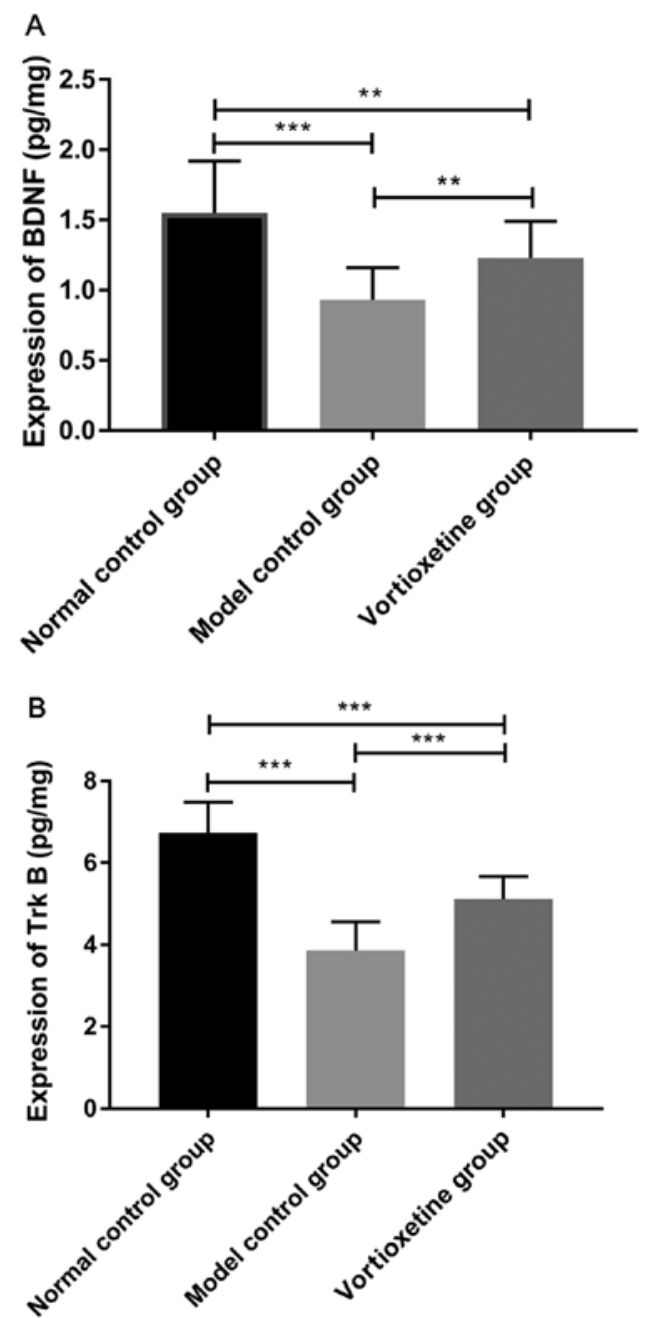

Figure 2. Expression of BDNF and Trk B in three groups. (A) The expression level of BDNF in Vortioxetine group was significantly higher than that in model control group $(\mathrm{P}=0.007)$, but lower than that in normal control group $(\mathrm{P}=0.006)$. The expression level of BDNF in model control group was significantly lower than that in normal control group $(\mathrm{P}<0.001)$. (B) The expression level of Trk B in Vortioxetine group was significantly higher than that in model control group $(\mathrm{P}<0.001)$, but lower than that in normal control group $(\mathrm{P}<0.001)$. The expression level of Trk $\mathrm{B}$ in model control group was significantly lower than that in normal control group $(\mathrm{P}<0.001) .{ }^{* *} \mathrm{P}<0.01$; ${ }^{* * * *} \mathrm{P}<0.001$. BDNF brain-derived neurotrophic factor; Trk $\mathrm{B}$, tyrosine kinase $\mathrm{B}$.

Comparison of expression levels of BDNF and Trk B. Comparing the expression of BDNF and Trk B in three 
groups, showed that the expression of BDNF in Vortioxetine group $(1.23 \pm 0.26 \mathrm{pg} / \mathrm{mg})$ was significantly higher than that in the model control group $(0.93 \pm 0.23 \mathrm{pg} / \mathrm{mg})(\mathrm{P}<0.05)$, but lower than that in the normal control group $(1.55 \pm 0.37 \mathrm{pg} /$ $\mathrm{mg})(\mathrm{P}<0.05)$. The expression of Trk B in the Vortioxetine group $(5.11 \pm 0.55 \mathrm{pg} / \mathrm{mg})$ was significantly higher than that in the model control group $(3.86 \pm 0.70 \mathrm{pg} / \mathrm{mg})(\mathrm{P}<0.05)$, but lower than that in the normal control group $(6.73 \pm 0.75 \mathrm{pg} / \mathrm{mg})$ $(\mathrm{P}<0.05)$ (Fig. 2).

\section{Discussion}

It has been mentioned in many studies that serotonin system is involved in psychological disorders such as depression and anxiety. As a neurotransmitter, serotonin regulates physiological processes such as mood, sleep and cognition. The lack of serotonin in synapses can lead to depression, and serotonin has to be mediated by corresponding receptors to play its role. Almost all subtypes of serotonin receptors are involved in antidepressant or antianxiety effects. Serotonin transporters also involve behavior, cognition and personality, as well as psychiatric disorders including depression, which take up serotonin in the synaptic cleft, leading to a decrease in synaptic serotonin levels (18-21). Vortioxetine may have a combined effect on a variety of serotonin receptors and serotonin transporters. The antidepressant effect is achieved by activating the relevant serotonin receptor and inhibiting the serotonin transporter, which is different from existing antidepressants. Vortioxetine also has memory enhancement effect (22).

In this study, we used stress to stimulate depression in rats. It was found that there were no differences in body mass, preference rate for sugar and water and field test among the three groups in the first week. However, with stimulation of source at the 2nd, 3rd and 4th week, there was no significant difference in body mass, sugar preference rate and field test exercise between Vortioxetine and model control group, and they were significantly lower than those of normal control group. At the 5th week, the body mass, sugar preference rate and field test of Vortioxetine group were significantly higher than those of model control group, but both groups were lower than the normal control group. The escape latency in Morris water maze was significantly lower than that in model control group in the first four days, but higher than that in normal control group. The target quadrant memory time in Vortioxetine group was significantly higher than that in model control group and lower than that in normal control group. These results indicated that with the occurrence of depression, rats suffer from loss of pleasure, decrease of autonomous and exploratory behavior, and decreased learning and memory. However, the use of Vortioxetine can alleviate the adverse symptoms of these depressed rats to a certain extent, and reduce the depression in depressed rats. Mahableshwarkar et al (23) assessed the effect of Vortioxetine on cognitive function in adult patients with severe depression, and found that Vortioxetine could significantly improve cognitive function and depression, and was well tolerated. This clinical result combined with our experimental results further suggested that Vortioxetine has a good therapeutic effect in depression.
ELISA was used to detect the expression of BDNF and Trk B in the hippocampus of three groups of rats. It was found that BDNF and TrkB in Vortioxetine group were significantly higher than those in model control group and significantly lower than those in normal control group. It has been reported that BDNF can promote neuronal differentiation, survival, maintenance and synaptic plasticity by activating high affinity receptor Trk B. BDNF-TrkB signal transduction deficiency is the pathogenesis of depression. The reactivation of BDNF-TrkB signal transduction by antidepressants can promote the recovery of patients (24). Since TrkB is a high-affinity receptor for BDNF, the role of BDNF requires TrkB signaling to BDNF to enhance the ability of synaptic transmission in the hippocampus. Synaptic transmission depends on the functional Trk B receptor. The lack of BDNF-TrkB signal due to the inhibitation of TrkB will reduce the antidepressant effect (25), which suggests that the BDNF-Trk B signaling pathway will participate in the antidepressant process. Kozono et al (26) reported that 5-HT4 receptor coupled with Gs protein can promote dendritic formation in hippocampal neurons, and increased expression of BDNF can induce 5-HT4 receptor to play a role by Trk B signal transduction. The function of voxoxetine is mainly carried out through the regulation of the serotonin system, which can promote the level of serotonin. It is 5-HT3, 5-HT7 and 5-HT1D receptor antagonists, 5-HT1B receptor partial agonists, 5-HT1 A receptor agonists and 5-HT transporters, so increasing serotonin is the key to futhioxetine. It has been reported (27) that BDNF can increase serotonin by activating Trk B, and the expression of serotonin increases after the expression of BDNF and Trk B is increased. According to a previous study (28), serotonin, BDNF, and Trk B can promote each other. Therefore, theoretically Vortioxetine can upregulate the expression of BDNF and Trk B in depressive rats by regulating the serotonin system, and BDNF and Trk B can further alleviate the symptoms of depressive rats. Sagud et al (29) used Vortioxetine to treat depression patients. The results showed that serotonin decreased and plasma BDNF increased in depression patients, which is similar to our results. In the study by Lu et al (30), it was also found that futhioxetine can increase the BDNF level in the hippocampus of depressive rats. However, the effect of futhioxetine on TrkB in the hippocampus of depressed rats has not been studied previously. It was found in this study that the expression of Trk B was also up-regulated.

However, it has been mentioned in some reports that the effects and side effects of Vortioxetine vary with the dose $(31,32)$. However, in this study, we only used a single dose of Vortioxetine, and it is not clear whether this dose is optimal. Considering the obvious symptoms of the disease and drug tolerance, the current drug treatment for depression is mainly individualized, mostly using several common drugs (33). We used Vortioxetine alone, and did not compare it with other common antidepressants or combination drugs. How other antidepressants and their combination affect the expression of BDNF and Trk B still needs to be explored. Vortioxetine might regulate BDNF-TrkB by regulating the serotonin system, which needs to be explored.

In conclusion, Vortioxetine can effectively alleviate the symptoms of depressed rats, such as loss of pleasure, 
autonomous and exploratory behavior, and decrease of learning and memory. The expression of BDNF and Trk B in the hippocampus of depressive rats was significantly lower than that of normal rats. Vortioxetine increased the expression of BDNF and Trk B in depressive rats and reduced their depressive behavior.

\section{Acknowledgements}

Not applicable.

\section{Funding}

No funding was received.

\section{Availability of data and materials}

The datasets used and/or analyzed during the present study are available from the corresponding author on reasonable request.

\section{Authors' contributions}

BS, YL and HX conceived and designed the study, and drafted the manuscript. BS, CQ, CL and PL collected, analyzed and interpreted the experimental data. BS revised the manuscript for important intellectual content. All authors read and approved the final version of the manuscript.

\section{Ethics approval and consent to participate}

The study was approved by the Animal Ethics Committee of Taian City Central Hospital (Taian, China) (no. TCH19001B).

\section{Patient consent for publication}

Not applicable.

\section{Competing interests}

The authors declare that they have no competing interests.

\section{References}

1. Ahmed R, Khan NA, Waseem M and Khan ZJ: Holistic approach in the management of depression: A Review. J Integ Comm Health 6: 10-14, 2017.

2. World Health Organization (WHO): Depression and other common mental disorders. Global Health Estimates (GHE), Geneva, Switzerland pp24, 2017

3. Siu AL, Bibbins-Domingo K, Grossman DC, Baumann LC, Davidson KW, Ebell M, García FA, Gillman M, Herzstein J, Kemper AR, et al; US Preventive Services Task Force (USPSTF) Screening for depression in adults: US Preventive Services Task Force recommendation statement. JAMA 315: 380-387, 2016

4. Duman RS, Aghajanian GK, Sanacora G and Krystal JH: Synaptic plasticity and depression: New insights from stress and rapid-acting antidepressants. Nat Med 22: 238-249, 2016.

5. Su CL, Su CW, Hsiao YH and Gean PW: Epigenetic regulation of BDNF in the learned helplessness-induced animal model of depression. J Psychiatr Res 76: 101-110, 2016.

6. Zhou C, Zhong J, Zou B, Fang L, Chen J, Deng X, Zhang L, Zhao X, Qu Z, Lei Y, et al: Meta-analyses of comparative efficacy of antidepressant medications on peripheral BDNF concentration in patients with depression. PLoS One 12: e0172270, 2017.
7. De Vry J, Vanmierlo T, Martínez-Martínez P, Losen M, Temel Y, Boere J, Kenis G, Steckler T, Steinbusch HWM, Baets M, et al: TrkB in the hippocampus and nucleus accumbens differentially modulates depression-like behavior in mice. Behav Brain Res 296: 15-25, 2016.

8. Lapchak PA, Araujo DM and Hefti F: BDNF and trkB mRNA expression in the rat hippocampus following entorhinal cortex lesions. Neuroreport 4: 191-194, 1993.

9. David DJ, Tritschler L, Guilloux JP, Gardier AM, Sanchez C and Gaillard R: Pharmacological properties of vortioxetine and its pre-clinical consequences. Encephale 42: 1S12-1S23, 2016 (In French).

10. Frampton JE: Vortioxetine: A review in cognitive dysfunction in depression. Drugs 76: 1675-1682, 2016.

11. Thase ME, Danchenko N, Brignone M, Florea I, Diamand F, Jacobsen PL and Vieta E: Comparative evaluation of vortioxetine as a switch therapy in patients with major depressive disorder. Eur Neuropsychopharmacol 27: 773-781, 2017.

12. Baune BT, Sluth LB and Olsen CK: The effects of vortioxetine on cognitive performance in working patients with major depressive disorder: A short-term, randomized, double-blind, exploratory study. J Affect Disord 229: 421-428, 2018.

13. Nishimura A, Aritomi Y, Sasai K, Kitagawa T and Mahableshwarkar AR: Randomized, double-blind, placebo-controlled 8 -week trial of the efficacy, safety, and tolerability of 5, 10, and $20 \mathrm{mg}$ /day vortioxetine in adults with major depressive disorder. Psychiatry Clin Neurosci 72: 64-72, 2018.

14. Connolly KR and Thase ME: Vortioxetine: A new treatment for major depressive disorder. Expert Opin Pharmacother 17: 421-431, 2016.

15. Harrison JE, Lophaven S and Olsen CK: Which cognitive domains are improved by treatment with vortioxetine? Int $\mathbf{J}$ Neuropsychopharmacol 19: pyw054, 2016. doi: 10.1093/ijnp/ pyw054.

16. Lee B and Lee H: Systemic administration of curcumin affect anxiety-related behaviors in a rat model of posttraumatic stress disorder via activation of serotonergic systems. Evid Based Complement Alternat Med 2018: 9041309, 2018. https://doi. org/10.1155/2018/9041309.

17. Pooley AE, Benjamin RC, Sreedhar S, Eagle AL, Robison AJ, Mazei-Robison MS, Breedlove SM and Jordan CL: Sex differences in the traumatic stress response: The role of adult gonadal hormones. Biol Sex Differ 9: 32, 2018

18. Hatherall L, Sánchez C and Morilak DA: Chronic vortioxetine treatment reduces exaggerated expression of conditioned fear memory and restores active coping behavior in chronically stressed rats. Int J Neuropsychopharmacol 20: 316-323, 2017.

19. Żmudzka E, Sałaciak K, Sapa J and Pytka K: Serotonin receptors in depression and anxiety: Insights from animal studies. Life Sci 210: 106-124, 2018.

20. Yohn CN, Gergues MM and Samuels BA: The role of 5-HT receptors in depression. Mol Brain 10: 28, 2017.

21. Fisher PM, Ozenne B, Svarer C, Adamsen D, Lehel S, Baaré WF, Jensen PS and Knudsen GM: BDNF val66met association with serotonin transporter binding in healthy humans. Transl Psychiatry 7: e1029, 2017

22. Katona CL and Katona CP: New generation multi-modal antidepressants: Focus on vortioxetine for major depressive disorder. Neuropsychiatr Dis Treat 10: 349-354, 2014.

23. Mahableshwarkar AR, Zajecka J, Jacobson W, Chen Y and Keefe RS: A randomized, placebo-controlled, activereference, double-blind, flexible-dose study of the efficacy of vortioxetine on cognitive function in major depressive disorder. Neuropsychopharmacology 40: 2025-2037, 2015.

24. Talebian A, Robinson-Brookes K and Meakin SO: TrkB regulates $\mathrm{N}$-Methyl-D-aspartate receptor signaling by uncoupling and recruiting the brain-specific guanine nucleotide exchange factor, RasGrf1. J Mol Neurosci 67: 97-110, 2019.

25. Fukuda M, Takatori A, Nakamura Y, Suganami A, Hoshino T, Tamura Y and Nakagawara A: Effects of novel small compounds targeting TrkB on neuronal cell survival and depression-like behavior. Neurochem Int 97: 42-48, 2016.

26. Kozono N, Ohtani A and Shiga T: Roles of the serotonin 5-HT4 receptor in dendrite formation of the rat hippocampal neurons in vitro. Brain Res 1655: 114-121, 2017.

27. Rumajogee P, Madeira A, Vergé D, Hamon M and Miquel MC: Up-regulation of the neuronal serotoninergic phenotype in vitro: BDNF and cAMP share Trk B-dependent mechanisms. J Neurochem 83: 1525-1528, 2002. 
28. McMorris T: Developing the catecholamines hypothesis for the acute exercise-cognition interaction in humans: Lessons from animal studies. Physiol Behav 165: 291-299, 2016.

29. Sagud M, Nikolac Perkovic M, Vuksan-Cusa B, Maravic A Svob Strac D, Mihaljevic Peles A, Zivkovic M, Kusevic Z and Pivac N: A prospective, longitudinal study of platelet serotonin and plasma brain-derived neurotrophic factor concentrations in major depression: Effects of vortioxetine treatment. Psychopharmacology (Berl) 233: 3259-3267, 2016.

30. Lu Y, Ho CS, McIntyre RS, Wang W and Ho RC: Effects of vortioxetine and fluoxetine on the level of Brain Derived Neurotrophic Factors (BDNF) in the hippocampus of chronic unpredictable mild stress-induced depressive rats. Brain Res Bull 142: 1-7, 2018.
31. Thase ME, Mahableshwarkar AR, Dragheim M, Loft H and Vieta E: A meta-analysis of randomized, placebo-controlled trials of vortioxetine for the treatment of major depressive disorder in adults. Eur Neuropsychopharmacol 26: 979-993, 2016.

32. Li Y, Pehrson AL, Oosting RS, Gulinello M, Olivier B and Sanchez C: A study of time- and sex-dependent effects of vortioxetine on rat sexual behavior: Possible roles of direct receptor modulation. Neuropharmacology 121: 89-99, 2017.

33. McIntyre RS: The role of new antidepressants in clinical practice in Canada: A brief review of vortioxetine, levomilnacipran ER, and vilazodone. Neuropsychiatr Dis Treat 13: 2913-2919, 2017. 